suggests this book might be of interest to economic historians.

While this translation is most welcome, one misses the many scholarly notes that form so valuable a part of the Hoovers' work. Many of their notes do, in fact, refer to the "De Natura Fossilium", and some cross-reference to them would have been useful to the reader. However, a number of explanatory footnotes have been included with this translation, as well as indexes of mineral names in English, Latin and Greek. There is, unfortunately, no index of place-names. A few misprints and errors have been noticed, such as "agate" on p. 18, line 33, for "aetites".

This little volume should have a wide circulation, and it is to be hoped it will be followed by translations into English of other works by Agricola, particularly the "Bermannus" of 1530, of which a new German translation, by Dr. Wilsdorf, appeared as recently as 1.955.

JoAN M. EYLES

${ }^{1}$ See Nature, 176, 949 (1955).

\section{WISCONSIN SYMPOSIUM ON SOLAR ENERGY, 1953}

\section{Solar Energy Research}

Edited by Farrington Daniels and John A. Duffie. Pp. $x v+290+11$ plates. (London: Thames and Hudson, Ltd., 1955.) 30s, net.

$\mathrm{R}$ ESEARCH on the utilization of solar energy has received a very great impetus as a result of conferences that have been recently held in Arizona (see Nature, Jan. 21, p. 110). This book is a record of the proceedings of an earlier conference organized by Prof. Farrington Daniels at the University of Wisconsin, Madison, in September 1953. Though less ambitious than the Arizona meetings, the Madison conference offered the first opportunity for many of those actively engaged in solar research to come together and discuss their problems. The book consists of a series of chapters written by those attending the conference or invited to contribute, and covers most of the aspects of the utilization of solar energy. These may be summarized briefly under the following headings: collection of solar radiation in the form of low-grade heat (that is, below the normal boiling point of water, as used for water and house heating, and water distillation) ; concentration of the radiation by mirrors to produce high temperatures for melting metals and refractory materials; conversion of radiation to electricity, either by thermoelectric methods with heat as an intermediate stage, or by photovoltaic effects; photochemical effects in which the equilibrium of a chemical system is changed by the action of light; and photosynthetic processes through living plants.

An introduction by Prof. Farrington Daniels explains the object of the conference and is followed by a section on probable world energy demands in the future, in which P. C. Putnam predicts that in a hundred years time solar heat collectors might supply nearly 10 per cent of the world's dernand in the form of low-grade heat, though only 0.1 per cent in the form of power. Incidentally, 60 per cent is quoted for nuclear fuels and 25 per cent for fossil fuels. Knowledge of the influence of meteorology on solar radiation and measurement of solar radiation are essential for a study of applications, and these factors are discussed in the succeeding chapters.

The nine chapters which follow collate papers on space heating and domestic uses of solar energy, solar power, solar evaporation and distillation, atmospheric phenomena and conversion of solar to electrical energy, solar furnaces, photosynthetic and photochemical utilization of solar energy, the British point of view, and miscellaneous applications and suggestions for further work. An appendix by Dr. John A. Duffie, of the University of Wisconsin, contains a survey of United States patents on the subject and a bibliography. Most of the sections consist of three or four papers by well-known research workers on the subject, and describe in a clear and lucid manner the present state of knowledge and the future possibilities.

The object of the symposium was to summarize the situation regarding the utilization of solar energy, and it is possible that the recent world conference in Arizona was, in some respects, promoted by the interest aroused at this earlier meeting. Many people with thoughts on the future development of world energy resources are inquiring about the possibilities of utilizing solar energy directly. The contents of this book appear to have been arranged for the express purpose of explaining these, and are written in an easily readable style with adequate illustrations. The complete volume gives the best outline at present available of activities in the utilization of solar energy.

\section{THERMODYNAMICS FOR CHEMISTS AND CHEMICAL ENGINEERS}

The Principles of Chemical Equilibrium, with Applications in Chemistry and Chemical Engineering

By Prof. Kenneth Denbigh. Pp. xxi +491 . (Cambridge: At the University Press, 1955.) 42s, net.

$A \mathrm{~N}$ understanding of thermodynamics is essential $A$ for all who are concerned with quantitative aspects of chemical processes, and yet most students find its concepts too abstract for rapid assimilation. A major difficulty is that the link between thermodynamics and the familiar and easily comprehended molecular theory is statistical mechanies, and most teachers, and apparently most authors, are of the opinion that the student is even less receptive to this subject. The order of presentation of most courses of physical chemistry is therefore molecular theory, thermodynamics and, finally, statistical mechanics. One wonders whether the problem of presentation is not the root of the vast number of books on thermodynamics and whether this spate of texts, each one of which may have a different emphasis, approach and nomenclature, is not a further barrier to the understanding of the often benumbed student. Every teacher of this fascinating and fundamental subject must be assailed by doubts of this kind when he opens the pages of yet another volume.

None the less, Prof. Kenneth Denbigh's book is a welcome addition to the multitude. It is intended for students in their final year of a chemistry or a chemical-engineering degree course, who have already had some acquaintance with the elementary parts of the subject. 'The first part (100 pages) introduces the first and second laws, the usual thermodynamic 